\title{
RELATORIO DO ANNO 1922
}

Cumprindo o disposto na letra i) do artigo 114 do Decreto n. 11.530, de 18 de Março de 1915 e do n. XVII, do art. 9..$^{\circ}$ do Regimento Interno desta Faculdade, passo a fazer o relatorio minucioso de tudo quanto occorreu neste estabelecimento a respeito da ordem, disciplina, serviço militar, observancia das leis e do orçamento do anno lectivo de 1922.

Abertura dos trabalhos. - Na fórma do disposto no art. 74 do Decreto n. 11.530 , de 18 de Março de 1915 e do art. 143 do Regimento Interno desta Faculdade, os trabalhos deste Instituto de ensino abriram-se no dia 2 de Março, celebrando a Congregação dos Professores, nesse dia, a sua primeira reunião, por ter sido feriado o dia $1 .^{\circ}$, marcado para a eleição dos Presidente e'vice-Presidente da Republica.

Presença dos professores. - Na primeira reuniāo da Congregação do anno lectivo findo, realizada a 2 de Março, foi verificado que se achavam promptos para o curso os Professores Drs. Uladislau Herculano de Freitas, Antonio Amancio Pereira de Carvalho, Antonio Januario Pinto Ferraz, Manoel Pedro Villabaim, José Ulpiano Pinto de Souza, Candido Nazianzeno Nogueira da Motta, Gabriel José Rodrigues de Rezende, Raynaldo Porchat, Frederico Vergueiro Steidel, João Braz de Oliveira Arruda, Estevam de Araujo Almeida, Manoel Pacheco Prates, Manoel Aureliano de Gusmão, Theophilo Benedicto de Souza Carvalho, e José Joaquim Cardozo de Mello Neto, e os substitutos, na regencia de cadeiras, Drs. Raphael Corrêa de Sampaio e Braz de Souza Arruda, e os substitutos, que 
não regem cadeiras Drs. Spencer Vampré, José Augusto Cesar, Octavio Mendes, Francisco Antonio de Almeida Mo. rato e José de Alcantara Machado d'Oliveira.

Exame vestibular. - Na fórma do disposto no art. 62 do Regimento Interno, a inscripção para o exame vestibular, instituido pelo art. 77 letra $c$ ) do Decreto 11.530, de 1915, para a matricula no curso desta Faculdade, aberta a 2 de Janeiro de 1922 e encerrada a 12 do mesmo mez, e, reaberta a 7 de Março, de conformidade com o disposto no artigo 2. ${ }^{\circ}$ do Decreto n. 4228, de 30 de Dezembro de 1920, e a resolução do Conselho Superior do Ensino, tomada em seissão realizada a 23 de Fevereiro de 1921, foi encerrada a 15 do mesmo mez de março, tendo a ella concorrido oitenta e um (81) candidatos, sendo na 1 . $^{\mathrm{a}}$ epoca cincoenta e seis (56) e, na 2. ${ }^{a}$, vinte e cinco (25). O exame iniciou-se com a prova escripta, para os inscriptos na 1. ${ }^{a}$ epoca, no dia 16 de Janeiro, tendo terminado no dia 24 desse mesmo mez, e, para os inscriptos na $2 .^{a}$ epoca. no dia 28 de Março, tendo terminado no dia 30 desse mesmo mez. O resultado do julgamento desse exame foi o seguinte: Em Janeiro approvados 46, reprovados 2 e inhabilitados 8 - total 56; e, em Março, approvados 22, reprovados 2 e inhabilitado 1 - total - 25. (Annexo respectivo). A commissão julgadora desse exame foi constituida, na 1. a epoca dos Drs. Candido Nazianzeno Nogueira da Motta, Manoel Pacheco Prates, Manoel Aureliano de Gusmão, Theophilo Benedicto de Souza Carvalho, José Augusto Cesar e Spencer Vampré; e, na 2. ${ }^{a}$ epoca, dos Drs. Manoel Pacheco Prates, Manoel Aureliano de Gusmão, Raphael Corrêa de Sampaio, Theophilo Benedicto de Souza Carvalho, José Augusto Cesar e Spencer Vampré.

Horario das aulas. - Pela Congregação dos Professores, em sessão de 2 de Março, foi adoptado o Horario das aulas constante do Annexo respectivo.

Programmas de ensino. - Adoptados pelos Professores das cadeiras do curso, foi nomeada uma commissão 
composta dos Drs. Manoel Pedro Villaboim, Manoel Aureliano de Gusmão e Theophilo Benedicto de Souza Carvalho, a qual formulou o seu parecer, opinando pela sua approvação, parecer esse que foi approvado na mesma sessão de 2 de Março. Os programmas foram impressos e postos á venda na Thesouraria da Faculdade.

Designação de professores. - No correr do anno findo, foram designados os professores: Dr. Spencer Vampré, professor substituto da $1 .{ }^{\text {u }}$ secção, para preencher o logar de professor substituto da $5 .^{\mathrm{a}}$ secção, que está vago, para reger a $3 .^{a}$ cadeira do $10^{\circ}$ anno, em substituição ao Dr. Reynaldo Porchat, a $2 .^{a}$ cadeira do $2 .^{\circ}$ anno, em substituição ao Dr. José Joaquim Candozo de Mello Neto e a 4." cadeira do 5. ${ }^{\circ}$ anno, em substituição ao Dr. Manoel Pedro Villaboim; Dr. Braz de Sousa Arruda, professor substituto da $2 .^{a}$ secção, para reger a $2 .^{a}$ cadeira do $1 .^{\circ}$ anno, em substituição ao Dr. Uladislau Herculano de Freitas, e a $1 .^{a}$ cadeira do $2 .^{\circ}$ anno, cujo logar ainda não está preenchido; Dr. Raphael Corrêa de Sampaio, professor substituto da $4 .^{a}$ secção, para reger a $2 .^{a}$ cadeira do $3 .^{\circ}$ anno, em substituição ao Dr. Luiz Barbosa da Gama Cerqueira, a $2 .^{a}$ cadeira do $4 .^{\circ}$ anno, em substituição ao Dr. Candido Nazianzeno Nogueira da Motta, e a 2.. cadeira do 5." anno, em substituição ao Dr. José Manoel de Azevedo Marques; Dr. Octavio Mendes, professor substituto da $6 .^{\mathrm{a}}$ seicção, para reger a $1 .^{a}$ cadeira do $4 .^{\circ}$ anno, em substituição ao Dr. Gabriel José Rodrigues de Rezende; Dr. Francisco Antonio de Almeida Morato, então professor substi-

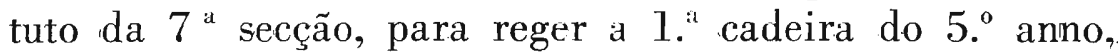
que ficou vaga com o fallecimento do Dr. Manoel Aurer liano de Gusmão, e para preencher o logar de professor substituto da $7 .^{a}$ secção, vago com a nomeação do mesmo Dr. Francisco Antonio de Almeida Morato para o logar de cathedratico de pratica do Processo Civil e Commercial; e Dr. José de Alcantara Machado d'Oliveira, professor substituto da 8." secção, para reger a $3 .^{a}$ cadeira do 5." 
anno, em substituição ao Dr. Antonio Amancio Pereira de Carvalho.

Inscripção para exames da segunda epoca. - Para os exames da 2. ${ }^{a}$ epoca, inscreveram-se 77 alumnos, sendo: no $1 .^{\circ}$ anno 9 , no $2 .^{\circ} 9$, no $3 .^{\circ} 38$, no $4 .^{\circ} 13$ e no $5 .^{\circ}-8$. $\mathrm{O}$ resultado desses exames consta do Annexo respectivo.

Inscripção de matricula. - Matricularam-se nos cinco annos do curso 362 alumnos, sendo: no $10^{\circ}$ anno 18 , no $2 .^{\circ} 63$, no $3 .^{\circ} 53$, no $4 .^{\circ} 116$ e no $5 .^{\circ} 49$.

Transferencia de matricula. - Durante o periodo das ferias, tres alumnos requereram guia de transferencia, sendo um do $3 .^{\circ}$ anno e um do $4 .^{\circ}$ anno para a Universidade do Rio de Janeiro e um do $5 .^{\circ}$ anno, para a Faculdade de Direito do Estado de Minas Geraes.

Licenças. - Durante o anno lectivo findo, estiveram no goso de licença, o Dr. Antonio Amancio Pereira de Carvalho, cathedratico da $3 .^{\text {a }}$ cadeira do $5 .^{\circ}$ anno, de 8 de Julho a 26 de Setembro; o Dr. Candido Nazianzeno Nogueira da Motta, cathedratico da $2 .^{a}$ cadeira do $4 .^{\circ}$ anno, de 17 de Abril a 12 de Novembro; o Dr. Gabriel José Rodrigues de Rezende, cathedratico da $1 .^{a}$ cadeira do $4 .^{\circ}$ anno, de 18 de Abril a 16 de Julho; o Dr. Luiz Barbosa da Gama Cerqueira, cathedratico da $2 .^{a}$ cadeira do $3 .^{\circ}$ anno, de 18 de Abril a 9 de Maio; o Dr. José Manoel de Azevedo Marques, cathedratico da $2 .^{a}$ cadeira do $5 .^{\circ}$ anno, de 16 de Novembro a 15 de Dezembro; e o Dr. José Joaquim Cardozo de Mello Neto, cathedratico da 2. ${ }^{a}$ cadeira do $2 .^{\circ}$ anno, de 27 de Abril a 27 de Novembro.

Fallecimento. - No dia 7 de Agosto, falleceu o Dr. Manoel Aureliano de Gusmão, professor cathedratico de Theoria e Pratica do Processo Civil e Commercial, com exercicio na $1 .^{\mathrm{a}}$ cadeira do $5 .^{\circ}$ anno.

Vaga do logar de professor cathedratico. - Com o fallecimento do Dr. Manoel Aureliano de Gusmão, ficou vaga a $1 .^{a}$ cadeira do $5 .^{\circ}$ anno. - Pratica do Processo Civil e Commercial. 
Nomeação e posse de professor cathedratico. - Por Decreto de 13 de Setembro, do Presidente da Republica, foi nomeado o Dr. Francisco Antonio de Almeida Morato, professor substituto da $7 .^{a}$ secção, para o logar de cathedratico da cadeira de Pratica do Processo Civil e Commercial ( $1 .^{a}$ do $5 .^{\circ}$ anno), vaga com o fallecimento do respectivo cathedratico - Dr. Manoel Aureliano de Gusmão, tendo o mesmo tomado posse e entrado no exercicio desse cargo, no dia 2 de Outubro.

Vaga do logar de professor substituto. - Com a posse do Dr. Francisco Antonio de Almeida Morato, professor substituto da 7." secção, no logar de cathedratico da $1 .^{a}$ cadeira do $5 .^{\circ}$ anno, ficou vago o logar de professor substituto da referida 7." secção.

Serviço Publico. - Durante o anno findo, estiveram ausentes desta Faculdade por motivo de serviço publico: o Dr. Uladislau Herculano de Freitas, Director, como representante desta Faculdade, no Conselho Superior de Ensino, de $1 .^{\circ}$ de Fevereiro a 8 de Março e de 16 de Julho a 7 de Agosto; o Dr. Reynaldo Porchat, como representante desta Faculdade, no Conselho Superior do Ensino, de 1. ${ }^{\circ}$ de Fevereiro a 8 de Março e de 16 de Julho a 7 de Agosto; o Dr. Manoel Pedro Villaboim, com assento no Congresso Nacional, como Deputado por este Estado de S. Paulo, de 12 de Março a 31 de Dezembro; e o Dr. José Manoel de Azevedo Marques, como Ministro das Relações Exteriores, de 1. ${ }^{\circ}$ de Janeiro a 15 de Novembro.

Substituições. - No correr do anno lectivo findo, o Dr. Antonio Amancio Pereira de Carvalho, professor cathedratico mais antigo e vice-Director, na fórma da lei, substituiu ao Dr. Uladislau Herculano de Freitas, no exercicio do cargo de Director, de $1 .^{\circ}$ de Fevereiro a 8 de Março; o Dr. Antonio Januario Pinto Ferraz, como professor mais antigo em exercicio, na falta do vice-Director, na fórma da lei, substituiu ao Dr. Uladislau Herculano de Freitas, no exercicio do cargo de Director, de 16 de Julho a 7 de 
Agosto; o Dr. Spencer Vampré, substituto da $1 .^{a}$ secção, de $1 .^{\circ}$ de Abril a 31 de Dezembro, substituiu ao Dr. Manoel Pedro Villaboim, na regencia da $4 .^{a}$ cadeira do $5 .^{\circ}$ anno, de 27 de Abril a 27 de Novembro, ao Dr. José Joaquim Cardozo de Mello Neto, na regencia da $2 .^{a}$ cadeira do $2 .^{\circ}$ anno, e, de 16 de Julho a 7 de Agosto, ao Dr. Reynaldo Porchat, na regencia da $3 .^{a}$ cadeira do $10^{\circ}$ anno; o Dr. Braz de Sousa Arruda, substituto da 2. ${ }^{a}$ secção, de 16 de Julho a 7 de Agosto, substituiu ao Dr. Uladislau Herculano de Freitas, na regencia da $2 .^{a}$ cadeira do $10^{\circ}$ anno; o Dr. Raphael Corrêa de Sampaio, substituto da $4 .^{a}$ secção, de $1 .^{\circ}$ de Janeiro a 15 de Dezembro, substituiu ao Dr. José Manoel de Azevedo Marques, na regencia da $2 .^{a}$ cadeira do $5 .^{\circ}$ anno, de 17 de Abril a 12 de Novembro, ao Dr. Candido Nazianzeno Nogueira da Motta, na regencia da $2 .^{a}$ cadeira do $4 .^{\circ}$ anno, e, de 18 de Abril a 9 de Maio, ao Dr. Luiz Barbosa da Gama Cerqueira, na regencia da $2 .^{a}$ cadeira do $3 .^{\circ}$ anno; o Dr. Octavio Mendes, substituto da 6. ${ }^{a}$ secção, de 18 de Abril a 13 de Agosto, substituiu ao Dr. Gabriel José Rodrigues de Rezende, na $1 .^{a}$ cadeira do $4 .^{\circ}$ anno; o Dr. Francisco Antonio de Almeida Morato, substituto da $7 .^{a}$ secção, de 8 de Agosto a $1 .^{\circ}$ de Outubro, substituiu ao Dr. Manoel Aureliano de Gusmão, na regencia da $1 .^{a}$ cadeira do $5 .^{\circ}$ anno, que ficou vaga no dia 7 de Agosto; e o Dr. José de Alcantara Machado d'Oliveira, substituto da $8 .^{a}$ secção, de 8 de Julho a 26 de Setembro, substituiu ao Dr. Antonio Amancio Pereira de Carvalho, na regencia da $3 .^{a}$ cadeira do $5 .^{\circ}$ anno. Defeza de theses. - Durante o anno lectivo findo, realizaram-se, nesta Faculdade, duas defesas de theses, de dois candidatos, que, em Agosto de 1921, se inscreveram para a revalidação de seus diplomas, conferidos por Faculdades extrangeiras, depois de cumpridas as disposições do art. 108 do Decreto 11.530, de 18 de Março de 1915, e dos arts. 150, 158, 165 e 169 a 185 do Regimento Interno desta Faculdade, sendo no dia 8 de Maio, a do ba- 
charel Amilcar Mendes Gonçalves, formado pela Faculdade de Direito de Paris, e no dia 9 de Maio a do bacharel Antonio Gomes do Amaral Filho, formado pela Oriental Universidade de Washington, do Districto de Columbia, dos Estados Unidos da America do Norte, tendo sido o primeiro approvado com os votos dos Drs. Uladislau Herculano de Freitas, Raphael Corrêa de Sampaio, Francisco Antonio de Almeida Morato e José Augusto Cesar, que compunham a commissão examinadora, e o segundo reprovado com os votos dos Drs. Uladislau Herculano de Freitas, Raphael Corrêa de Sampaio, Spencèr Vampré e Octavio Mendes, que compunham a Commissão examinadora. Inscripção para o preenchimento dos logares vagos de professores substitutos. - De conformidade com o Aviso de 3 de Dezembro de 1919, para verificar-se a hypothese prevista no artigo 51 do Deçreto 11.530 , de 18 de Março de 1915, por edital expedido a 5 e publicação a 6 de Junho, cuja copia foi enviada a esse Ministerio com o ofifcio n. 10, de 6 do mesmo mez, foi aberta, pelo prazo de trinta dias, a inscripção dos candidatos que, independentemente de concurso, se quizessem habilitar ao provimento do logar de professor substituto da 5. ${ }^{a}$ secção, que estava vago, e que comprehendia: Economia Politica, Sciencia das Finanças e Direito Administrativo, tendo a ella concorrido os candidatos bachareis; Luiz Silveira e José Maria Mac-Dowell. Esses dois candidatos apresentaram trabalhos, mas a Congregação dos professores, em sessão realizada a 10 de Julho seguinte, tomando conhecimento das inscripções, resolveu regeitar os trabalhos apresentados pelos dois mencionados candidatos, por não considerar esses trabalhos obra verdadeiramente notavel, nos termos do art. 51 do Decreto n. 11.530, de 1915, em consequencia do que esta Directoria ordenou que fosse, por edital, annunciada a inscripção para o preenchimento desse logar. 
Por edital expedido a 15 e pubricado a 16 de Julho, e cuja copia foi enviada a esse Ministerio, com o officio n. 17, de 17 do mesmo mez, de conformidade com o disposto nos arts. 43,44 e 45 do Decr. 11.530 e dos arts. 44 e 45 do Regimento Interno desta Faculdade, foi aberta, pelo prazo de cento e vinte dias, a contar dessa data, a inscripção para o preenchimento do logar vago de professor substituto da 5. ${ }^{\text {a }}$ secção desta Faculdade, que comprehendia as materias seguintes: Economia Politica, Sciencia das Finanças e Direito Administrativo. Dentro do prazo legal, inscreveram-se os cinco candidatos seguintes: 1) Bacharel Antonio de Sampaio Doria, a 24 de Julho;

2) Bachiarel José Maria Mac-Dowell, a 9 de Agosto; 3) Bachárel Americo Braziliense Antunes de Moura, a 14 de Agosto; 4) Bacharel Mario Corrêa de Camargo Aranha, a 2 de Setembro; e 5) Bacharel Luiz Silveira, a 8 de Novembro. Em sessão da Congregação dos professores, realizada a 16 de Novembro, para os fins dispostos na letra b) do art. 45 do Decreto 11.530, de 1915, resolveu a Congregação, por proposta do Dr. Reynaldo Porchat, unanimemente approvada, nomear uma commissão composta dos professores Drs. Reynaldo Porchat, Francisco Antonio de Almeida Morato e Spencer Vampré, para dar parecer sobre os trabalhos apresentados pelos candidatos inscriptos no concurso para o preenchimento do logar vago de professor substituto da 5. ${ }^{a}$ secção, examinar esses trabalhos e declarar, si os mesmos estavam de accordo com a lei que rege os concursos de professores, sem prejuizo da eleição dos professores que, na fórma do disposto no art. 45 letra $b$ ) do Regimento Interno, combinado com o disposto no art. 70 letra $i$ ) do Decreto 11.530, de 1915, com os cathedraticos da secȩão, deverão compôr a mesa examinadora dos candidatos inscriptos nessa 5 . $^{2}$ secção. Em seguida, procedendo-se á eleição dos professores que faltavam para a composição da referida mesa examinadora, foram eleitos os Drs. Reynaldo Porchat e Spencer Vampré, e como sup- 
plentes, os Drs. João Braz de Oliveira Arruda e Francisco Antonio de Almeida Morato. Em sessão da Congregação, realizada a 26 de Dezembro, a commissão nomeada em sessão de 16 de Novembro anterior, apresentou seu parecer, declarando que os trabalhos apresentados pelos candidatos inscriptos bachareis Antonio de Sampaio Doria, Americo Braziliense Antunes de Moura, Mario Corrêa de Carnargo Aranha e Luiz Silveira, satisfizeram a exigencia do art. 45 letra $a$ ) do Decreto 11.530 de 1915 e do art. de egual numero e letra do Regimento Interno desta Faculdade, e que os apresentados pelo candidato Bacharel José Maria Mac-Dowell - "Fronteiras Nacionaes", "Da Participação Nos Lucros" e "Da Organização Do Orçamento E Sua Verificação", comquanto aproveitaveis e versantes sobre as materias das disciplinas da $5 .^{a}$ secção, não eram, entretanto, obras systematicas, nem estudos sobre qualquer das questóes approvadas pela Congregação, pelo que esse candidato decahira do direito de proseguir nas provas do concurso, por inobservancia do preceito do art. 45 letra a) do Regimento Interno e do Decreto 11.530, de 1915. Submettido á discussão e a votos esser parecer, foi o mesmo unanimemente approvado, na referida sessão de 26 de Dezembro.

Quanto ao concurso para o preenchimento do logar de professor substituto da $7 .^{a}$ secção, vago pela nomeação e posse do respectivo professor para o logar de cathedratico da cadeira de Pratica do Processo Civil e Commercial, devo relatar que, por edital expedido a 4 de Outubro e publicado a 5 do mesmo mez e, de conformidade com o Aviso de 3 de Dezembro de 1919, para verificar-se a hypothese prevista no art. 51 do Dec. 11.530, de 1915, e cuja copia foi enviada a esse Ministerio, com o officio n. 29 de 9 do mesmo mez, foi aberta, pelo prazo de trinta dias, a inscripção dos candidatos que independentemente de concurso, se quizessem habilitar ao provimento do logar de professor substituto da 7." secção, que comprehende: 
"Theoria do Processo Civil e Commercial e Pratica do Processo Civil e Commercial", não tendo a ella concorrido candidato algum, em consequencia do que, por edital expedido a 6 e publicado a 7 de Outubro, e cuja copia foi enviada a esse Ministerio, ccm o officio $n$. desse mesmo mez, de conformidade com o disposto nos arts. 43, 44 e 45 do Decr. 11.530, de 1915 e dos arts. 44 e 45 do Regimento Interno desta Faculdade, foi aberta, pelo prazo de cento e vinte dias, a contar dessa data, a inscripção para o preenchimento do logar vago de Professor substituto da $7^{\text {a }}$ secção, que comprehende as materias seguintes: Theoria do Processo Civil e Commercial e Pratica do Processo Civil e Commercial, á qual já se apresentou, no dia 2 de Dezembro, o Bacharel Jorge Americano.

Proposta sobre mudança de cadeiras. - Pelo professor cathedratico Dr. João Braz de Oliveira Arruda, em sessão da Congregação dos professoreses, realizada a 21 de Outubro de 1921, foi apresentada a indicação seguinte: "Indico que o estudo da Philosophia do Direito seja feito no $5 .^{\circ}$ anno, passando uma das cadeiras do $5 .^{\circ}$ anno para o $4 .^{\circ}$, e ensinando-se Direito Civil no $1 .^{\circ}$ anno, no $2 .^{\circ}$ e no $3 .^{\circ}$, de modo que a parte geral do Direito Civil seja ensinada no $1 .^{\circ}$ anno - Sustentação - E' pensamento vencedor, que se deveria começar no curso juridico, o ensino pela Encyclopedia Juridica, considerada como sendo uma introducção ao estudo do Direito, uma disciplina, por assim dizer, propedeutica, e que se deveria terminar pelo ensino da Philosophia Juridica, a qual exige, para ser bem comprehendida pelo alumno, já certo habito de abstrahir, e de raciocinar, já ưn certo cabedal de ideas e de noçóes juridicas, que não posșue o alumno, ao entrar para a Faculdade. Como se acha hoje, no limiar dos estudos juridicos, leva a Philosophia do Direito o estudante a ter repugnancia pelas sciencias ensinadas nesta Academia, nã̃o só desanimado pela difficuldade que encontra em entender alguns dos arduos problemas juridico-sociaes, mas 
tambem porque, não lhe sendo dado penetrar no amago da matéria, terá de decorar sinão as palavras, ao menos o modo de argumentar do professor, cujas opinióes não está na altura de comprehender devidamente. A chamada Lei Rivadavia teve uma vaga idea desse problema, e mandou que se ensinasse, no $10^{\circ}$ anno, a Encyclopedia, como sendo disciplina introductoria, mas cahiu no extremo opposto, pois privou os moços de um estudo indispensavel, qual o de exame em conjuncto do que pertence aos varios ramos do saber juridico e mesmo das sciencias sociaes, attingindo as mais altas generalizaçõès a que pódem chegar as sciencias juridico-sociaes, coordenando os principios mais geraes dos diversos ramos do Direito, e integrando-os com principios novos, que não se acham em nenhuma das sciencias ensinadas nesta Faculdade. Além disso, a Encyclopedia não póde se occupar com o methodo de estudo ou de ensino, mas exclusivamente com o que se denomina technica juridica, em seu triplice aspecto de technica legislativa, doutrinal e judicial, assumpto que bem póde ser estudado na parte geral do Direito Civil, como o é por Ihering em seu Espirito Romano, por Demogue em suas Noçóes Fundamentaes do Direito Privado, e por muitos civilistas. Tomada a Encyclopedia como sendo um resumo, ou uma recapitulação do estudo das matérias com que se occupou o alumno durante o curso, é insufficiente, porque não leva ao conhecimento do methodo em geral, e em todas as applicações necessarias ao Direito, nem ta.nbem se interessa pela integração dos principios dos varios ramos do saber juridico. Foi a indeterminação do campo da Encyclopedia Juridica que levou certos espiritos á creação de uma nova sciencia, que denominaram Theoria Geral do Direito, a qual é tamberm incompleta, e parece ter tido a vida ephemera da rosa de Malherbes. - Dar os principios mais geraes da sciencia juridica, quer na parte geral, quer na especial de cada capitulo das várias sciencias, servir ao estudante de roteiro da região em que 
vae peregrinar, é sem duvida funcção que se póde attribuir á Encyclopedia, e que pertence tambern á Theoria Geral do Direito, mas conceber o edificio em toda a sua magestade, fixar todas as linhas, mostrar os pontos em que se funda o monumento secular, os alicerces, as columnas e a cupula da obra, aquellas partes em que está ainda a trabalhar, os retoques soffridos, as substituições, os processos de construcção, de reparo ou de reconstrucção, dar novos instrumentos, novos processos para o trabalho colossal da construcção, ensinar principios novos para os que examinam a obra, eis o que só a Philosophia Juridica póde fazer, determinando os principios fundamentaes do Direito, mostrando os processos de reforma, entrando incidentemente pelo estudo historico das instituições, apresentando os problemas insoluveis da sciencia, e occupando-se com asumptos que não cabem no quadro de nenhuma das disciplinas estudadas no curso desta Faculdade. Pelo que fica dicto, é claro que uma cadeira de Encyclopedia deveria ser creada no curso juridico, sendo collocada no $1 .^{\circ}$ anno, e que a Philosophia deveria ser attribuida ao 5. ${ }^{\circ}$ Como porém supprir essa falta com as cadeiras que actualmente se encontram nesta Faculdade? Entendo que si, em logar de ser ensinado o Direito Civil no $2 .^{\circ}$ anno, no $3 .^{\circ}$ e no $4 .^{\circ}$, o fosse no $1 .^{\circ}$, no $2 .^{\circ}$ e no $3 .^{\circ}$, facilmente se resolveria o problema, uma vez que o professor da cadeira do $10^{\circ}$ anno tivesse o cuidado de muito se extender sobre a parte geral do Direito Civil, a qual, práticamente falando, póde bem supprir o estudo da Encyclopedia. E' pôr mim affirmado do ponto de vista práctico, porque realmente o objecto da Encyclopedia é muito mais vasto que o da parte Geral do Direito Civil. Este estudo da parte fundamental do Direito, da menos mutavel, da mais geral, da, por assim dizer, constante da nossa sciencia, corresponde, de certo modo, ao do antigo Direito $\mathrm{Na}$ tural, que procurava, por processos imperfeitos, investigar qual é o amago do Direito, quaes os seus principios ne- 
cessarios, universaes e incondicionaes, chegando unicamente a fixar o que de mais geral se encontra na sciencia, e portanto de menos mutavel. Era, de facto, o Direito Natural uma sciencia cerebrina, ao passo que a parte geral do Direito fixa, com exactidão, qual a constancia dos principios juridicos, e como se evolve o Direito. Dois pontos porém, para a realização dessa reforma reclamada por todos e sempre desejada pelo nosso saudoso companheiro Dr. Lessa, merecem deliberação longa, e resolução firme, e ser producto de grande meditação, por parte de nossa Faculdade, e vem a ser a determinação da cadeira que, do $5 .^{\circ}$ anno, deverá passar para o $4 .^{\circ}$, e o estabelecimento de providencias tendentes a facilitar essa mudança, tendo em attenção que os alumnos que passam agora dos annos inferiores para os superiores já fizeram o curso de Philosophia e os que se matriculam agora vão se encontrar, em uma só turma, com os que estão no 2.", continuando a complicação em nossa Faculdade durante 4 annos. São as difficuldades que sempre occorrem na mudança da seriação das matérias. - Quanto á primeira. parece-me de menor importancia. Eu não vejo cadeira que, do $5 .^{\circ}$ anno, não possa passar para $0.4^{\circ}$, e entendo que se póde transferir do $5 .^{\circ}$ para o $4 .^{\circ}$, sem prejuizo: ou a cadeira de Medicina Publica, pois não tem grande dependencia com outras disciplinas juridicas, nem mesmo com a cadeira de Direito Penal; — ou a de Direito Administrativo, que nenhum preparo exige dos alumnos para o estudo de disciplina do que se occupa, e que poderia ficar até no $1 .^{\circ}$ anno, como está a cadeira de Direito Constitucional; - ou a de Theioria do Processo Criminal, pois não vejo em que seja o estudo completo do Direito Penal indispensavel para a bôa comprehensão do Processo; ou a cadeira de Practica do Processo Civil e Commercial, porque seria no $4 .^{\circ}$ anno, um complemento da cadeira de Theoria do Processo Civil e Commercial, que lhe está já attribuida; - ou a cadeira de Direito Internacional Pri- 
vado, que, comquanto exija o conhecimento de Direito Commercial e de Processo, todavia exige somente noçôes fundamentaes dessas duas materias, e não conhecimento completo de todas as particularidades, de todos os segredos de taes sciencias, o que seria impossivel dar a um rapaz que está cursando uma Faculdade de Direito, e é digno de lembrar-se que, segundo o programma approvado por nossa Congregação, só do ponto 52 começam as referencias á fallencia e ao processo, do qual se occupa o professor unicamente com os actos processuaes em geral, com as rogatorias e com a execução da sentença fóra do territorio, assumptos que conhece o alumno na cadeira de processo, logo ás primeiras licçôes, quando aprende o que é um processo, quaes seus actos eśsenciaes, o que é a citação e quão importante é que as sentenças sejam executadas. Em conclusão, pois, umá só difficuldade se me depara em relação ao primeiro obice, e vem a ser o embaraço da escolha da cadeira a ser transferida, pois qualquer o póde sem o menor damno para o ensino. Em egualdade de condições, eu preferia mudar a de Direito Internacional Privado, porque foi disciplina ensinada no $2 .^{\circ}$ anno, e nunca o professor accusou ter notado inconveniente em ser ella posta no começo do curso juridico. E' pois de experiencia didactica que não ha necessidade de se achar tal sciencia no ultimo anno do curso. - Quanto á segunda difficuldade transitoria, encontro tres soluções. A primeira é confiar ao professor de Philosophia um curso de tres annos de Direito Civil, assim o occupando nos annos em que teria de ficar ocioso. Só vejo um inconveniente neste alvitre, e vem a ser a pouca força moral que tem um professor que ensina disciplina para a qual não fez um concurso regular. A segunda é a reunião de turmas, a qual só teve inconvenientes em relação á manutenção, em uma unica sála, de alumnos do $10^{\circ}$ anno e do $5 .^{\circ}$, e isto mesmo porque o professor não attendeu á susceptibilidade dos quintannistas. A terceira é o desdobramento 
das turmas, quando numerosas, chamando-se um substituto para reger a cadeira desdobrada, e dando-se lhe uma remuneração por conta da Faculdade, como é de justiça, em consequencia do maior serviço a que é forçado. Eis os motivos que me levam a formular esta indicação, e peço licença para lembrar que, no ultimo trabalho que escreveu o Dr. Lessa, de saudosissima memoria para a nossa Faculdade, dava elle a opinião que ora defendo como sendo hoje pacificamente acceita pelos juristas, que se sccupam com o ensino do Direito, por todos os professores de Direito. - São Paulo, 21 de Dezembro de 1921 - - (assignado:-João Arruda." A Congregação dos professores, nessa mesma sessão, resolveu nomear uma commissão para dar parecer sobre essa indicação, para ser apresentado na proxima reunião da mesma Congregação, remettendo a Secretaria a cada um dos professores uma copia da referida indicação, sendo, então, nomeados para esse effeito, os professores Drs. José Ulpiano Pinto de Souza, José Joaquim Cardozo de Mello Neto e Raphael Corrêa de Sampaio. Tendo o Dr. José Ulpiano pedido excusa e o Dr. Cardozo de Mello Neto entrado no gozo de licença, foram nomeados, em suas substituições, os Drs. Manoel Pacheco Prates e Manoel Aureliano de Gusmão. A commissão que, então, ficou composta dos Drs. Manoel Pacheco Prates, Raphael Corrêa de Sampaio er Manoel Aureliano de Gusmão, apresentou o seu parecer a respeito, o qual era do tê̂r seguinte: Parecer -- A commissão nomeada para examinar a indicação do Sr. Professor Dr. João Arruda pensa cumprir o seu dever, apresentando ao alto criterio desta respeitavel Congregação a seguinte Ponderação - Parece fóra de duvida que o estudo da Philosophia do Direito deve ser feito no ultimo anno da Faculdade. - A indicação alterada, porem, exige previamente a indispensavel creação de uma cadeira de "Encyclopedia Juridica, collocada no primeiro anno, como introducção ao estudo do Direito" — Esta necessidade in- 
controversa é reconhecida e de modo cathegorico proclamada pelo proprio e digno auctor da indicação, logo inicialmente a fls. 2 da respectiva justificação e ainda com a orientação que presidiu á formação do seu actual programma, que ministra aos principiantes, elementos introductivos ao estudo do Direito. - Sala das sessões da Congregação da Faculdade de Direito de S. Paulo em 7 de Julho de 1922. - (assignados Manoel Pacheco Prates Raphael Sampaio - A. de Gusmão" - A 10 de Julho, reunida a Congregação, convocada para tratar desse e de outros assumptos, foram, nessa mesma sessão, lidos a re. ferida indicação e o parecer previamente apresentado pela commissão nomeada, e, submettidos ambos á discussio, depcis de sobre o assumpto terem falado o autor da indicação e os membros da commissão nomeada, o Dr. Joẫo Arruda apresentou a seguinte indicação: — "Indico que, ccndo creada a cadeira de Encyclopedia Juridica e approvada a passagem da cadeira de Philosophia do Direito para o ultimo anno, sejam as disciplinas ensinadas na Faculdade distribuidas por seis annos, ficando ao Conselho Superior o encargo de estabelecer a seriação das materias, para a uniformidade do ensino nas Faculdades brasileiras. - São Paulo, 10 de Julho de 1922. - (assignado) - João Arruda" Submettidas á discussão as duas indicações apresentadas pelo Dr. João Arruda, conjunctamente, com o parecer formulado pela commissão nomeada, e, em seguida, á votação, são as indicações e o parecer approvados, contra o voto do Dr. José Ulpiano. As indicações e o parecer, supra referidos, foram remettidos ao Dr. Presidente do Conselho Superior do Ensino para os devidos effeitos com o officio, n. 8, de 10 do mesmo mez de Julho.

Representação da Faculdade junto ao Congresso Juridico e Congresso do Ensino. - Tendo o Presidente do Congresso Juridico commemorativo da Independencia do Brasil convidado a Congregação idesta Faculdade a enviar 
um seu representante junto ao Congresso Juridico promovido pelo Instituto da Ordem dos Advogados Brasileiros, a reunir-se de 16 a 31 de Outubro, no Rio de Janeiro, resolveu a Congregação, por unanimidade e votos, em sessão de 2 de Outubro, designar o Professor cathedratico - Dr. Manoel Pedro Villaboim, então no Rio de Janeiro, como o seu representante junto ao mesmo Congresso. O mesmo Professor foi designado para representar a Faculdade no Congresso do Ensino a reunir-se tambem no Rio de Janeiro.

Acquisição de apolices federaes. - Por esta Directoria foram adquiridas, durante o anno, duzentas e sessenta e tres (263) apolices da divida publica da União, do valor de um conto de réis (rs. 1:000\$000), cada uma, ao juro de cinco por cento $(5 \%)$, para a constituição do patrimonio desta Faculdade.

Inscripção para exames da primeira epoca. - Para estes exames, inscreveram-se 300 alumnos, sendo: no $1 .^{\circ}$ anno 70 , no $2 .^{\circ}-45$, no $3 .^{\circ}-41$, no $4 .^{\circ}-97$, e no $5 .^{\circ}-470$ resultado desses exames consta do Annexo respectivo.

Collação de grau. - Durante o anno lectivo findo, foi collado o grau de Bacharel em Sciencias Juridicas e Sociaes a quarenta e nove (49) bacharelandos, dos quaes seis (6) concluiram o seu curso na segunda epoca de 1921, e quarenta e dois (42) o concluiram na primeira epoca do anno lectivo findo, e urn em consequencia de revalidação de diploma expedido pela Faculdade de Direito de Pariz. Desses 49 Bachareis, 33 são naturaes do Estado de São Paulo; 5 do de Minas Geraes; 2 da Cidade do Rio de Janeiro; 2 do Estado do Rio de Janeiro; 2 do de Sergipe; 1 do de Pernambuco; 1 do de Santa Catharina; 2 da Italia e 2 de Portugal. (Annexo respectivo).

Cartas de Bacharel. - Durante o anno findo, foram expedidas cento e uma (101). Cartas a egual numero de Bachareis formados em Sciencias Juridicas e Sociaes, 
sendo cem (100) formados por esta Faculdade e um formado pela Faculdade de Direito de Paris, e cujo diploma foi revalidado nesta Faculdade, depois de approvado em defeza de theses. Desses 101 Bachareis são naturaes: do Estado de São Paulo, 75; do de Pernambuco 9; da Cidade do Rio de Janeiro 4; do Estado do Rio de Janeiro 3; do de Paraná 2; do de Pernambuco 1; do da Bahia 1 ; do de Ceará 1; do de Santa Catharina 1; do de Rio Grande do Sul 1, e da Italia 3. (Annexo respectivo).

Serviço militar. - De conformidade com a informação prestada pelo respectivo Instructor, durante o anno findo, frequentaram a instrucção militar apenas sete alumnos desta Faculdade, tendo prestado exame somente tres, dos quaes foram - approvado 1 e reprovados 2, tendo faltado ás provas 4 .

Sessões da Congregação. - No correr do anno findo, a Congregação dos professores celebrou sete (7) sessões, nas quaes foram tratados diversos assumptos.

Procedimento dos alumnos. - $\mathrm{O}$ procedimento dos alumnos, no decorrer do anno lectivo findo, foi bom, nada tendo occorrido digno de menção.

Bibliotheca. - A Bibliotheca desta Faculdade foi frequentada, durante o anno findo, por 6.627 pessôas, que consultaram 2.790 obras em 5.911 volumes, sendo em Portuguez 2.011; em frances 511; em italiano 93; em hespanhol .76; em latim 52 e em inglez 47, estando no numero dos consulentes 2.614 pessôas, que leram jornaes ei revistas (Annexo respectivo).

Os empregados da Bibliotheca bem cumpriram os seus deveres.

Thesouraria. - O Balanço demonstrativo da Thesouraria desta Faculdade, constante do Annexo respectivo. fe chado a 31 de Dezembro findo, accusa que da Receita e Despeza ha um saldo de 713:738 $\$ 400$ (setecentos e treze contos setecentos e trinta e oito mil e quatrocentos réiśs. assim distribuidos: no Banco do Commercio e Industria de 
São Paulo. rs. $514 \$ 200$ (quinhentos e quatorze mil eı duzentos réis), no Banco do Brasil - 27:224\$200 (vinte sete contos duzentos e vinte e quatro mil e duzentos réis), e 686:000 $\$ 000$ seiscentos e oitenta e seis contos de rs.), valor de 686 apolices da União, do valor de um conto de réis' (1:000\$000), cada uma, e ao juro de cinco por cento $(5 \%)$ ao anno.

O saldo apurado em 1921, foi de 644:738\$064 (seiscentos e quarenta e quatro contos setecentos e trinta e oito mil e sessenta e sete réis), havendo, portanto, uma differença a mais de 69:733\$333 (sessenta e nove contos setecentos e trinta e tres mil trezentos e trinta e tres réis).

O Thesoureiro bem cumpriu os seus deveres.

Secretaria. - Os serviços da Secretaria estiveram sempre em dia, tendo os empregados bem cumprido os seus deveres.

Secretaria da Faculdade de Direito de São Paulo, em 24 de Janeiro de 1923.

\section{O Director:}

Dr. Uladislal Herculano de Freitas. 